\section{A DECISÃO MOTRIZ DO LEVANTADOR NO VOLEIBOL: REVISÃO DE LITERATURA E SISTEMATIZAÇÃO PARA ENSINO-APRENDIZAGEM SEGUNDO A PRAXIOLOGIA MOTRIZ}

\author{
THE MOTOR DECISION FOR SETTING IN VOLLEYBALL: LITERATURE REVIEW \\ AND SYSTEMATIZATION FOR TEACHING-LEARNING ACCORDING TO MOTOR \\ PRAXEOLOGY
}

\author{
LA DECISIÓN MOTRIZ DEL LEVANTADOR EN EL VOLEIBOL: REVISIÓN DE \\ LITERATURA Y SISTEMATIZACIÓN PARA ENSEÑANZA Y APRENDIZAJE \\ SEGÚN LA PRAXIOLOGÍA MOTRIZ
}

\section{Felipe Menezes Fagundes*, João Francisco Magno Ribas*}

Palavras chave:

Voleibol.

Levantador.

Praxiologia Motriz.

Decisão.
Resumo: Este artigo objetiva identificar e sistematizar os elementos para decisão motriz no levantamento no voleibol evidenciados nas produções científicas a partir das interações motrizes de cooperação e oposição. Realizou-se uma revisão de literatura sobre a decisão motriz no levantamento que encontrou 14 artigos e 19 capítulos de livro sobre 0 tema. A maioria dos artigos é aplicada e objetivou analisar ações de levantamento ou o conhecimento tático dos levantadores, por meio de entrevista ou observação de vídeo. Os capítulos de livro mostraram maior produção depois da década de 2000, bem como um entendimento mais global sobre o levantamento. Entre os vários elementos para decisão citados, bloqueio adversário ganhou destaque, seguido de qualidade da recepção/defesa. Por fim, propôs-se uma sistematização cíclica para ensino-aprendizagem baseado nesses elementos, a partir dos conceitos da Praxiologia Motriz.
Keywords: Volleyball. Setter. Motor Praxeology. Decision.

Abstract: This article finds and systematizes elements for motor decision when setting in volleyball evidenced in scientific works based on motor interactions of cooperation and opposition. A literature review about the motor decision during setting found 14 articles and 19 book chapters. Most articles are applied and they analyzed setting actions or setters' tactical knowledge using interviews or video observation. Book chapters increased after the 2000s as well as a more global understanding about setting. Blocking opponents gained prominence among the various elements cited for decision as well as reception/ defense quality. Finally, a cyclic systematization was proposed for teaching-learning based on these elements, under Motor Praxeology concepts.

Palabras clave:

Voleibol.

Pasador.

Praxiología Motriz.

Decisión.
Resumen: Este artículo objetiva identificar y sistematizar los elementos para la decisión motriz en el levantamiento en el Voleibol, evidenciados en las producciones científicas a partir de las interacciones motrices de cooperación y oposición. Se ha realizado una revisión de literatura sobre la decisión motriz en el levantamiento. Fueron encontrados 14 artículos y 19 capítulos de libro acerca del tema. La mayoría de los artículos tuvieron como objetivo analizar acciones de levantamiento o el conocimiento táctico de los levantadores, a través de entrevista o de observación de vídeos. Los capítulos de libro mostraron mayor producción después de la década de 2000 , así como un entendimiento más global acerca del levantamiento. Entre los elementos para decisión citados, el bloqueo adversario tuvo destaque, seguido de la calidad de la recepción/defensa. Por fin, se ha propuesto una sistematización cíclica para enseñanza y aprendizaje basados en esos elementos, a partir de los conceptos de la Praxiología Motriz.
*Universidade Federal de Santa Maria. Santa Maria, RS, Brasil. E-mail: felipemfagundes@ live.com, ribasifm@ hotmail.com

Recebido em: 14-03-2017 Aprovado em: 28-07-2017

DOI: http://dx.doi.org/10.22456/1982-8918.71854 (c) (1) (8) Licence 


\section{INTRODUÇÃOO}

O voleibol evidencia-se como um fenômeno sociocultural de estrondosa relevância no campo da Educação Física, o que corrobora sua existência nos diversos campos de atuação dessa área de conhecimento, articulado como ferramenta educacional, como meio de integração social, como alta performance, entre outros (TUBINO, 1992). Dessa maneira, o voleibol conquistou milhões de pessoas por seu dinamismo, tornando-se uma modalidade encantadora, tanto para praticantes quanto para admiradores de esportes.

Segundo Fagundes, Oliveira e Ribas (2015), a restrição das ações dos jogadores ao uso exclusivo da habilidade motora rebater suscita constantes decisões no voleibol, executadas no espaço de tempo em que a bola realiza sua trajetória no ar. Nesse sentido, perceber esses elementos, interpretá-los e optar pela melhor decisão nesse instante de tempo são demandas essenciais de quem busca atuar acertadamente no voleibol. Com esse paradigma de compreensão do funcionamento dos esportes e jogos, a Praxiologia Motriz evidencia-se como uma consolidada área de conhecimento que sistematiza a lógica interna de todas as práticas motrizes, a partir das interações motrizes que os jogadores estabelecem com as diferentes estruturas de cada jogo/esporte (LAGARDERA; LAVEGA, 2003).

Pautado nisso, Ribas (2014) apropriou-se dos conceitos da Praxiologia Motriz e sistematizou 0 jogo de voleibol em momentos (saque, recepção, levantamento, ataque, bloqueio e defesa), caracterizando as interações motrizes estabelecidas entre eles. Ao considerar as possibilidades de interação motriz dos jogadores, o levantador configura-se como uma das mais complexas funções do voleibol, em que a interpretação dos elementos do jogo é ação primordial, ao entender sua tarefa como organizador das ações ofensivas da equipe (CARVALHO, 1978; FRÖHNER, 2012). Para isso, ele precisa considerar inúmeros elementos que se evidenciam nas diferentes situações, aspectos condicionantes para realização da melhor opção de ataque em cada ação de levantamento (RIBEIRO, 2008; MACHADO, 2006; DÜRRWÄCHTER, 1984). Ribas, Araújo e Zimmermann (2014) sistematizaram as interações estabelecidas nesse momento do jogo na figura abaixo.

Figura 1 - Interações motrizes estabelecidas no levantamento no voleibol

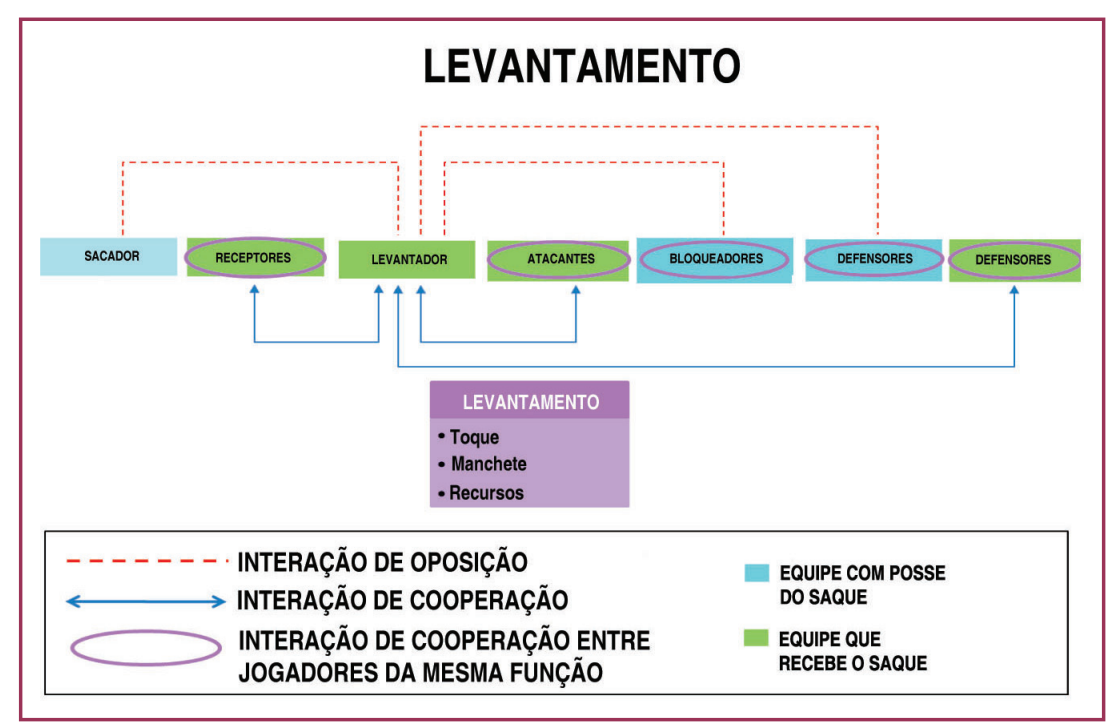

Fonte: Adaptado de Ribas, Araújo e Zimmermann (2014, p. 82) 
Dessa forma, o levantador analisa constantemente as ações de todos os jogadores, ao passo que coopera com companheiros e opõe-se aos adversários a cada ação no jogo (RIBAS; ARAÚJO; ZIMMERMANN, 2014). Ao considerar sua relevância no contexto do jogo, o levantamento é um momento de extrema complexidade, que demanda um trato pedagógico específico, utilizando-se de métodos de ensino que possibilitem esse desenvolvimento. Nesse sentido, percebe-se que, mesmo havendo uma produção científica sobre métodos que rompe com a perspectiva tecnicista (Método Situacional, Teaching Games for Understanding...), prevalecem os métodos tradicionais para o desenvolvimento esportivo (RIBAS, 2014).

Partindo do exposto, evidencia-se a necessidade de compreender como a produção científica vem tratando o processo de ensino-aprendizagem do levantador no voleibol. Ao considerar essa premissa, o presente estudo visa identificar os elementos para decisão motriz no levantamento evidenciados nas produções científicas da área a partir das interações motrizes de cooperação e oposição e sistematizá-los indicando os conhecimentos que deverão ser contemplados para o ensino-aprendizado a partir da Praxiologia Motriz.

\section{BASES TEÓRICAS}

No que diz respeito a conhecer as particularidades de um esporte ou jogo, a Praxiologia Motriz se configura como uma área de conhecimento fidedigna na análise da dinâmica de funcionamento das manifestações da cultura de movimento. Para seu criador, o professor francês Pierre Parlebas (2001, p. 354), a Praxiologia Motriz mostra-se como "[...] a ciência da ação motriz e especialmente das condições, modos de funcionamento e os resultados do seu desenvolvimento". Para Lagardera e Lavega (2003), a Praxiologia Motriz objetiva estudar a lógica interna dos jogos e dos esportes a partir de suas regras de funcionamento.

A lógica interna, para Parlebas (2001, p. 302), é um "[...] sistema de características pertinentes de uma situação motriz e das consequências que acarretam para a realização da ação motriz correspondente". O autor explica que a lógica interna se dá basicamente a partir das regras do jogo e, ao embasar seu ponto de vista, utiliza-se do voleibol como exemplo, apontando suas características, como a presença simbólica de rede, campos separados e invioláveis, ausência de contato, alternância regulamentada de ações e duração da partida com base na pontuação (PARLEBAS, 2001). Dessa maneira, a lógica interna impõe uma série de papéis que orientam as diferentes possibilidades de atuar dos participantes em cada contexto, a partir das regras.

É nesse sentido que se concretiza a universalidade do conceito ação motriz como o centro das discussões em Praxiologia Motriz. Sua relevância se constitui de tal forma que a expressão Teoria da Ação Motriz se aplica com frequência ao referir-se a essa área de conhecimento. Parlebas (2001, p. 41) conceitua ação motriz como "[...] o processo de realização das condutas motrizes de um ou vários sujeitos que atuam em determinada situação motriz". Dessa forma, compreende-se que a ação motriz deriva da lógica interna de determinada prática, cada esporte/jogo irá propor uma forma de atuação para seus participantes, diretamente relacionado à lógica interna.

Mas no que se pauta a lógica interna de uma prática motriz? A partir do que se evidencia nas regras do jogo/esporte, sejam essas institucionalizadas ou combinadas pelos jogadores, a 
lógica interna constitui-se a partir das possíveis interações motrizes do(s) jogador(es) com os demais participantes, com o espaço, com o tempo e com o material (PARLEBAS, 2001). Isso significa que toda e qualquer ação motriz realizada em determinada situação estará vinculada às possíveis interações do sujeito ao considerar as características estruturais apresentadas pela prática motriz.

Ao arquitetar sua compreensão sobre as possibilidades de interações motrizes dos jogadores, a Praxiologia Motriz construiu seu alicerce teórico embasado pela Semiologia. Parlebas (2001, p. 406) concretizou o conceito de Semiotricidade, caracterizado como "[...] natureza e campo das situações motrizes, consideradas desde o ponto de vista da aplicação de sistemas de signos associados diretamente à conduta motriz dos participantes".

Nesse sentido, Parlebas (2001) concluiu que os jogadores, ao interagirem em um sistema praxiológico, realizam emissões e interpretações de mensagens (signos) constantemente. Isso significa que, ao realizar determinada ação motriz, o jogador emite mensagens suscetíveis à leitura com relação ao seu comportamento motor, configurando a Comunicação Práxica. A Comunicação Práxica constitui as características definidoras das situações sociomotrizes, o que permite compreender as ações dos jogadores à medida que se inserem em uma unidade global, atrelando sentido às suas atuações (PARLEBAS, 2001). Ela subdivide-se em Comunicação Práxica Direta e Comunica Práxica Indireta.

A Comunicação Práxica Direta faz menção à forma como as ações serão executadas em relação aos companheiros e aos adversários (PARLEBAS, 2001). Quando se realiza a recepção no voleibol, objetiva-se proporcionar as condições ideais para que o levantador opte pela melhor situação ofensiva. Esse cenário caracteriza a comunicação motriz (ou cooperação), pois todas as ações e mensagens serão as mais claras possíveis, no intuito de facilitar as leituras dos demais companheiros. Em contrapartida, quando se realiza um ataque, o jogador irá dificultar ao máximo as ações dos adversários, sejam bloqueadores ou defensores, para que obtenha triunfo na conquista do ponto, para dificultar a interpretação dos adversários em relação a sua ação, o que configura contracomunicação motriz (ou oposição) (RIBAS, 2014).

Já a Comunicação Práxica Indireta se associa à decodificação dos comportamentos motores dos demais jogadores como veículos de mensagem, a qual também se subdivide em duas possibilidades de manifestação, o gestema e o praxema. 0 primeiro, como sua própria nomenclatura já sugere, está vinculado a gestos e códigos realizados pelos praticantes como substituição ao uso da fala, realizando uma indicação específica (PARLEBAS, 2001). O praxema, por sua vez, constitui-se da "conduta motriz de um jogador como um símbolo, cujo significante é o comportamento motor observável e cujo significado é o projeto tático correspondente a dito comportamento, tal e como é percebido" (PARLEBAS, 2001, p. 349). Dessa forma, a Comunicação Práxica Indireta atrela significado às ações e comportamentos dos participantes no jogo, ao interferir diretamente na decisão motriz dos jogadores com base nos elementos de leitura percebidos nos processos de leitura.

\section{DECISÕES METODOLÓGICAS}

Este estudo caracteriza-se como uma revisão de literatura, ao considerar o problema de pesquisa exposto, o caminho metodológico adotado, o processo de busca, as estruturas de análise e forma de apresentação, interpretação e organização dos dados utilizados. Para 
Gil (2008, p. 50), a revisão de literatura "[...] é desenvolvida a partir de material já elaborado, constituído principalmente de livros e artigos científicos". Esta investigação também se configura como teórica, pois está debruçada em estudar teorias, consolidar conceitos, formular referências científicas e fortalecer concepções e ideologias (DEMO, 1995).

As características deste estudo também o configuram como uma investigação bibliográfica e explicativa, bem como esclarecem Lakatos e Marconi (2003) ao apontar que a finalidade da investigação bibliográfica é deixar o pesquisador ciente sobre o que foi escrito, dito ou filmado em relação a determinado tema. Para Gil (2008, p. 27), as pesquisas explicativas "[...] têm como preocupação central identificar os fatores que determinam ou que contribuem para a ocorrência de fenômenos". Este estudo dividiu-se em duas etapas: $1^{a}$ ) Identificação, seleção das bases de dados e levantamento de informação; $2^{\mathfrak{a}}$ ) Análise, sistematização e discussão dos dados.

O processo de pesquisa considerou os estudos que discutiram o levantamento no voleibol a partir da função do levantador e da análise de seu papel na dinâmica do jogo. Restringiu-se 0 processo de busca por obras escritas em português, a partir dos seguintes descritores: voleibol, levantador, levantamento, decisão, distribuição e cognição. Nessa perspectiva, foram considerados estudos produzidos até hoje sem recorte temporal, em virtude da especificidade do tema e de sua restrita discussão acadêmica. Como fontes para pesquisa, foram utilizados os indexadores Scielo e Centro Esportivo Virtual, bem como do Google Acadêmico. Por fim, consultaram-se os portais online de revistas brasileiras na área de Educação Física, as quais apresentam pertinência na especificidade e alcance consolidados no cenário acadêmico. Não se delimitou um critério quanto ao Qualis Capes em virtude de muitos dos artigos contemplados na pesquisa não pertencerem a revistas indexadas, o que limitaria o estudo. Assim, foram contemplados nesse processo os seguintes periódicos: Revista Brasileira de Ciência do Esporte, Movimento, Motrivivência, Revista Brasileira de Educação Física e Esporte, Revista de Educação Física, Revista Motriz, Revista Mackenzie de Educação Física e Esporte, Revista Ciência e Movimento, Revista Motricidade, Pensar a Prática, Revista Mineira de Educação Física.

Para seleção dos livros utilizados na pesquisa, consultou-se o acervo da biblioteca de uma instituição pública que possui graduação e programa de pós-graduação em Educação Física. Além disso, consideraram-se também as obras presentes no acervo do grupo de pesquisa e na coletânea pessoal dos pesquisadores. Nesse processo, utilizou-se a palavra-chave "voleibol" como mecanismo de busca no sistema de biblioteca da instituição, o qual evidenciou 42 obras do acervo da biblioteca e duas obras da coletânea particular. Em seguida, refinou-se a busca a partir da temática explícita nos objetivos e características das obras, totalizando 19 capítulos selecionados para este estudo.

Para interpretação das obras, foi utilizada a Análise de Conteúdo temático-categorial (OLIVEIRA, 2008). A Análise de Conteúdo é considerada um conjunto de técnicas para interpretação da comunicação, seja essa oral ou escrita, com procedimentos sistemáticos para sua compreensão aprofundada (BARDIN, 2011; FRANCO, 2005). Para Bardin (2011), a Análise de Conteúdo constitui-se das etapas pré-análise, codificação e interpretação/inferência. 0 processo de pré-análise seguiu os padrões acima expostos, ao passo que a codificação foi realizada por organização das obras a partir de unidades temáticas que geraram categorias específicas em cada tipo de produção. Essas categorias possibilitaram a interpretação dos dados obtidos na pesquisa de forma interligada com base nas sessões temáticas estabelecidas pela problemática em voga. Para isso, realizou-se a leitura na íntegra de todos os artigos e capítulos evidenciados 
na pesquisa, com o intuito de realizar uma criteriosa análise do conteúdo dessas obras. Por fim, sistematizaram-se os elementos para decisão motriz do levantador a partir dos pressupostos teóricos da Praxiologia Motriz para o processo de ensino-aprendizagem, estruturado em ciclos específicos.

Salienta-se que não foi objetivo desta pesquisa discutir o processo de tomada de decisão, mas sim apresentar os elementos cruciais para o levantador considerar nas ações de levantamento. É evidente que as ações motrizes do levantador são pautadas pelo processo de tomada de decisão, no entanto, esta pesquisa priorizou apresentar os aspectos relevantes para desenvolvimento da decisão motriz do levantador ao invés de discutir esse processo no contexto do voleibol. Além disso, este estudo considerou o conceito decisão motriz como compreensão dos processos cognitivos relacionados à realização das ações motrizes dos jogadores. A decisão motriz é caracterizada como a pré-decisão em resposta a uma pré-percepção que acarreta atos de antecipação motriz (PARLEBAS, 2001). Optou-se pela utilização desse conceito em virtude das aproximações teóricas propostas nos objetivos da pesquisa e das correntes epistemológicas adotadas nessa investigação.

\section{ANÁLISE E DISCUSSÃO}

Para facilitar a apresentação, comparação e discussão dos dados obtidos na pesquisa, optou-se pela construção de figuras e quadros que expressam os dados quantitativos relativos aos resultados. Será apresentada a análise dos artigos e, em seguida, dos capítulos de livro.

Selecionaram-se 14 artigos científicos que apresentaram relação com o levantamento e o processo de decisão motriz. Foram analisados e classificados os objetivos das pesquisas, 0 impacto da divulgação pelo Qualis Capes 2014 na Educação Física, tipos de estudos, métodos, formas de análise e sujeitos de cada um dos estudos dessa investigação. Já quanto aos elementos para decisão motriz do levantador, ao considerar o objetivo de sistematizá-los para o processo de ensino-aprendizagem, optou-se por apresentá-los juntamente com os demais elementos evidenciados nos capítulos de livros, em virtude da similaridade apresentada nas duas formas de publicação e para melhor interpretação. Nesse sentido, a Figura 2 evidencia um gráfico que sintetiza os objetivos estabelecidos e o impacto de divulgação do periódico considerando o Qualis Capes 2014.

Figura 2 - Objetivos e o Qualis Capes das publicações

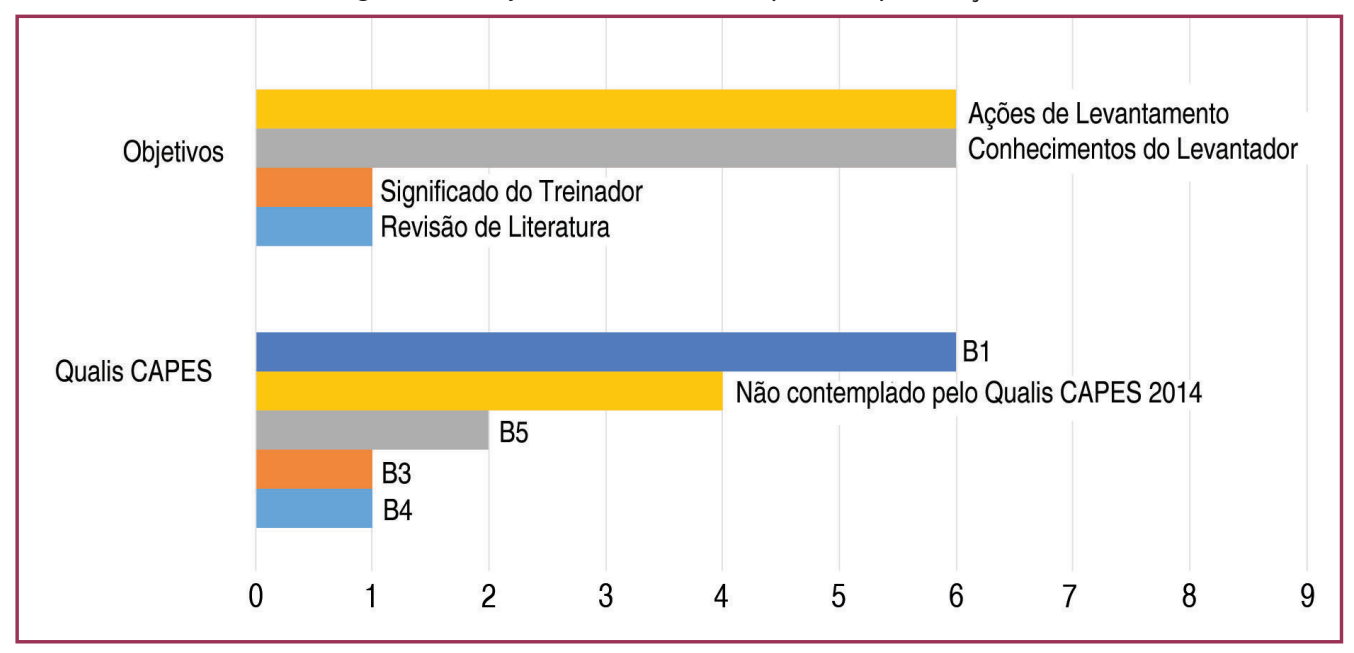


Esse gráfico evidencia que os pesquisadores visam compreender, em suma, como os levantadores organizam sua distribuição no voleibol, ao considerar que seis dos 14 artigos contemplados na pesquisa objetivaram analisar as ações de levantamento e outros seis evidenciaram os conhecimentos do levantador referente a esse momento do jogo. Alguns dos artigos que analisaram as ações do levantador focaram suas discussões na efetividade da obtenção do ponto em cada posição da quadra, não apresentando elementos para decisão motriz em seu discurso. No entanto, os artigos que salientaram os conhecimentos do levantador apresentaram maior diversidade de elementos para a decisão motriz do levantador.

Já quanto ao Qualis Capes de publicação dos artigos, fica claro que a temática é pertinente no campo acadêmico, pois boa parcela dos artigos foi publicada em periódicos reconhecidos na área. No entanto, quatro publicações estão presentes em periódicos que não estão contemplados no Qualis Capes 2014. Visto os objetivos estabelecidos nos artigos, necessitou-se identificar suas características metodológicas, esquematizadas na figura abaixo.

Figura 3 - Características metodológicas dos artigos científicos

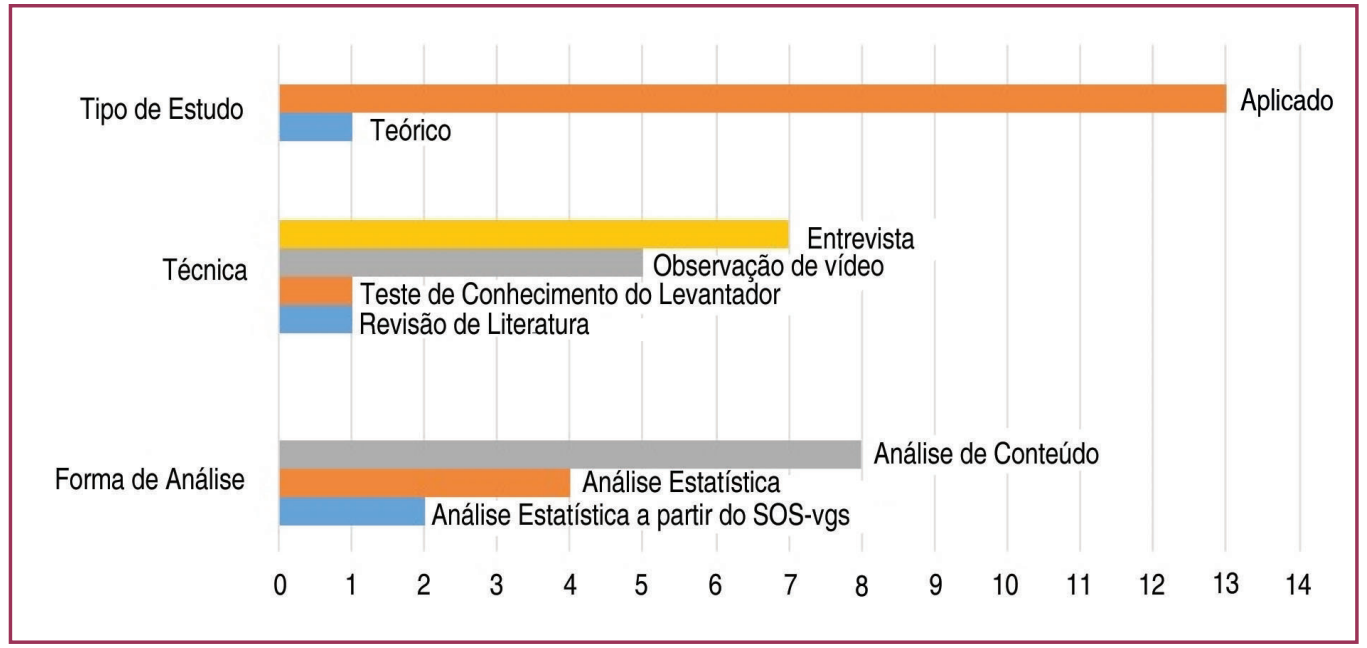

Fonte: Coleta de dados, 2016.

Quanto às características metodológicas, do total de 14 artigos, 13 deles são aplicados, o que corrobora uma tendência dos periódicos em aceitar produções acadêmicas desse tipo. Outra explicação pela pouca discussão teórica pode estar relacionada à própria necessidade de produção de conhecimento referente ao tema que, no contexto brasileiro, ainda é incipiente. Deve-se destacar também a similaridade dos objetivos das pesquisas, o que implica um caminho metodológico semelhante, contudo, com diferentes sujeitos e formas de análise que corroboram a pertinência dos estudos.

Quanto aos métodos adotados para as investigações, a entrevista e a observação figuraram como principais ferramentas utilizadas. Os estudos que empregaram entrevista evidenciaram o conhecimento declarativo dos levantadores, enquanto que as investigações que recorreram à observação de vídeo analisaram a execução das ações de levantamento em diferentes contextos. É importante ressaltar que, na classificação das pesquisas por categorias, considerou-se a metodologia informada pelos próprios pesquisadores nas 
investigações, ao passo que não se analisou a fidedignidade dos caminhos metodológicos indicados.

No que diz respeito aos tipos de análise dos artigos, a Análise de Conteúdo e a Análise Estatística predominaram, corroboradas pelos tipos de pesquisa e métodos utilizados nos estudos. Contudo, dois artigos realizaram as análises a partir do Sistema de Observação e Avaliação do Levantador (SOS-vgs) que, segundo Matias e Greco (2011b, p. 1011), "é um instrumento de observação e avaliação da distribuição do levantador em situação real de jogo (via abordagem quantitativa)". Os demais estudos estatísticos utilizaram categorias pautadas em diversas fontes, não seguindo um protocolo preestabelecido.

Após conhecer os caminhos metodológicos desenhados para a realização das pesquisas sobre a decisão motriz do levantador, mostra-se necessário conhecer quem são os protagonistas desses estudos. Em seguida, serão contextualizados os perfis dos sujeitos que foram considerados nessas pesquisas.

Figura 4 - Sujeitos da pesquisa contemplados nos estudos

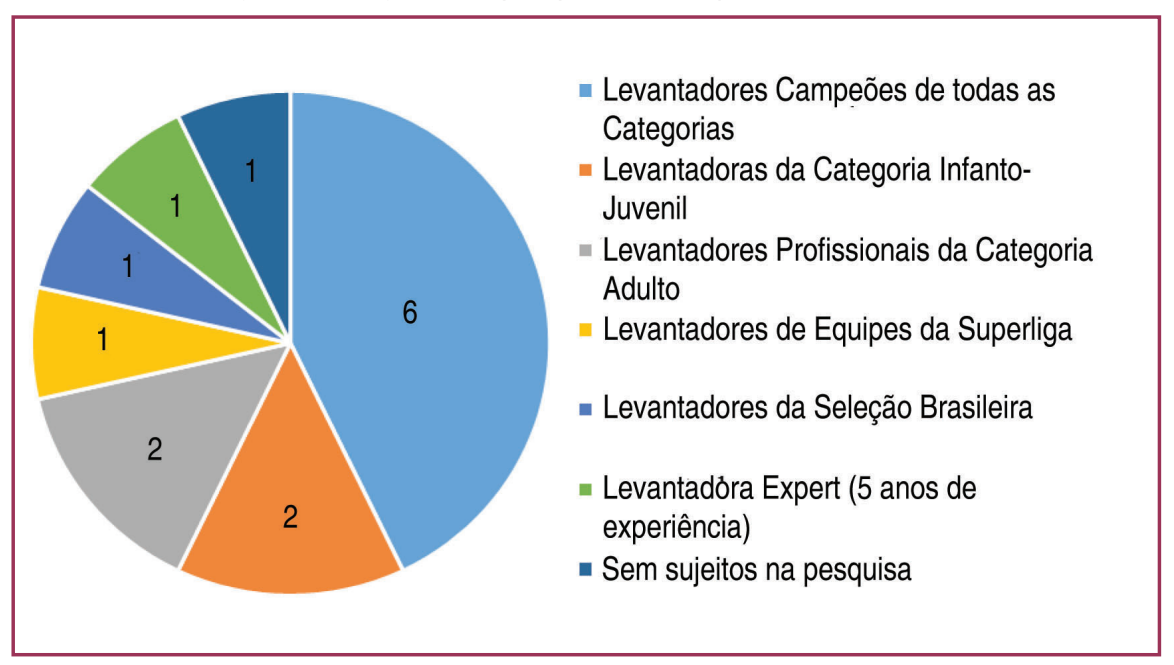

Fonte: Coleta de dados, 2016.

Ao analisarem-se os sujeitos em questão, mostra-se nítida a estreita relação das investigações acadêmicas com os esportes de alto desempenho. Nos artigos, percebe-se que seis deles consideraram os levantadores campeões de diversas categorias e outros dois estudos restringiram-se a levantadores profissionais adultos. Outras categorias também foram contempladas, mas em menor número. $O$ único estudo que não apresenta sujeitos se dispôs a fazer uma revisão bibliográfica da relevância do levantador no sucesso do voleibol brasileiro.

Posto fim às discussões referentes aos artigos científicos, será apresentada a discussão sobre os 19 capítulos de livros selecionados para este estudo. Salienta-se que não foi encontrado nenhum livro que se propôs a discutir o levantamento exclusivamente. Dessa forma, a pesquisa se restringiu a livros sobre voleibol que discutissem esse momento do jogo em seu conteúdo. Para sistematização das obras, considerou-se o número de publicações por décadas, classificadas a partir dos aspectos encontrados na discussão sobre o levantamento, descritas na figura abaixo. 
Figura 5 - Número de Publicações e Análise de Conteúdo dos capítulos agrupados por década da publicação

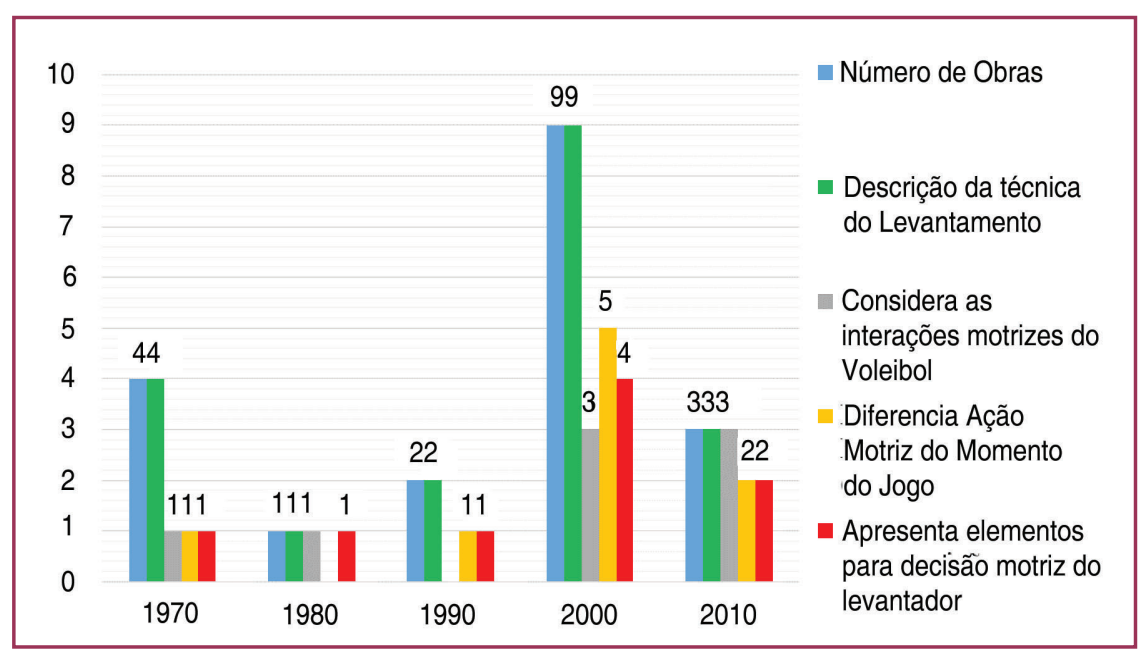

Fonte: Coleta de dados, 2016.

Ao analisar o gráfico, percebe-se que a descrição da técnica do levantamento esteve presente em todos os capítulos e a maioria deles entende a ação motriz do toque como forma correta de executá-lo. Fica nítido que, além de um aumento nas produções a partir de 2000, as obras apresentam uma compreensão para além da reprodução técnica, considerando as interações motrizes estabelecidas e os elementos para decisão motriz. Evidenciou-se que pelo menos uma obra em cada década discutiu esses elementos e as interações motrizes do jogo, mesmo que indiretamente, fato esse que corrobora a pertinência dessa discussão. Para Fotía (2013) e Ribas (2014), interações motrizes e elementos para decisão motriz são aspectos essenciais do processo de ensino-aprendizagem do voleibol, em virtude de sua importância na organização das equipes e das leituras realizadas no contexto do jogo.

A partir disso, serão apresentados os elementos para decisão motriz citados nos artigos e nos capítulos de livro considerados nesta pesquisa. Construiu-se um quadro que representa os elementos e o número de obras em que ele foi citado. Evidencia-se que alguns elementos foram aglutinados para possibilitar a classificação a partir das categorias de análise. Entretanto, buscou-se manter o sentido original do termo.

Quadro 1 - Elementos para Decisão Motriz do Levantador

\begin{tabular}{|c|c|c|c|c|c|}
\hline \multirow[t]{2}{*}{$\begin{array}{l}\text { Elementos para Decisão } \\
\text { Motriz }\end{array}$} & \multicolumn{2}{|c|}{$\begin{array}{l}\text { Número de obras que } \\
\text { citaram o elemento }\end{array}$} & \multirow[t]{2}{*}{$\begin{array}{l}\text { Elementos para Decisão } \\
\text { Motriz }\end{array}$} & \multicolumn{2}{|c|}{$\begin{array}{l}\text { Número de obras } \\
\text { que citaram o } \\
\text { elemento }\end{array}$} \\
\hline & Artigos & Livros & & Artigos & Livros \\
\hline Total de Obras: & 14 & 19 & Total de Obras: & 14 & 19 \\
\hline Bloqueio Adversário & 14 & 7 & $\begin{array}{l}\text { Dificultar leitura do adversário } \\
\text { (contracomunicação) }\end{array}$ & 2 & 3 \\
\hline $\begin{array}{l}\text { Qualidade da Recepção ou } \\
\text { Defesa }\end{array}$ & 7 & 3 & Posição ineficaz do atacante & 1 & - \\
\hline Melhor Atacante & 6 & 3 & $\begin{array}{l}\text { Optar pelo jogador menos } \\
\text { eficaz em relação à } \\
\text { marcação ao melhor jogador }\end{array}$ & 1 & - \\
\hline $\begin{array}{l}\text { Momento do Jogo (placar e } \\
\text { aproveitamento) }\end{array}$ & 6 & 2 & $\begin{array}{l}\text { Posição do Levantador } \\
\text { Adversário }\end{array}$ & - & 1 \\
\hline
\end{tabular}


Continuação do quadro $1 .$.

\begin{tabular}{|l|c|c||l|c|c|}
\hline $\begin{array}{l}\text { Mudar distribuição para } \\
\text { prevenir adaptação do } \\
\text { adversário }\end{array}$ & 5 & 3 & $\begin{array}{l}\text { Optar pela maior distância } \\
\text { para o bloqueio adversário }\end{array}$ & 1 & 1 \\
\hline Características dos Atacantes & 5 & 2 & $\begin{array}{l}\text { Relação saque-bloqueio do } \\
\text { adversário }\end{array}$ & 1 & - \\
\hline Situações Imprevistas & 5 & - & Características das equipes & 1 & 1 \\
\hline $\begin{array}{l}\text { Estado Psicológico dos } \\
\text { Atacantes }\end{array}$ & 5 & - & $\begin{array}{l}\text { Posição de origem da } \\
\text { Recepção/Defesa }\end{array}$ & 1 & - \\
\hline $\begin{array}{l}\text { Adaptar a técnica e a direção } \\
\text { do levantamento }\end{array}$ & 5 & - & $\begin{array}{l}\text { Marcação na bola de } \\
\text { segunda }\end{array}$ & 1 & - \\
\hline $\begin{array}{l}\text { Jogar em relação ao bloqueio } \\
\text { adversário }\end{array}$ & 5 & - & Combinação de jogada & 1 & - \\
\hline Número de Atacantes & 3 & - & $\begin{array}{l}\text { Antecipação do central } \\
\text { adversário }\end{array}$ & 1 & - \\
\hline Treinador & 3 & - & $\begin{array}{l}\text { Posição e Tempo dos } \\
\text { Atacantes }\end{array}$ & & 2 \\
\hline Saque Adversário & 3 & - & & \\
\hline Não contempla elementos & 2 & 10 & &
\end{tabular}

Fonte: Coleta de dados, 2016.

Com esse panorama, percebeu-se que os artigos apresentam mais elementos para decisão motriz que os capítulos de livro, por sua especificidade científica. Quando analisados, vê-se que Bloqueio Adversário é quase unanimidade, pois 14 artigos e sete capítulos de livro 0 apontaram como elemento relevante no levantamento, assim como a Qualidade da Recepção/ Defesa, presente em sete artigos e três capítulos. Isso já era esperado pelas interações motrizes estabelecidas entre esses momentos do jogo, pois são consequentemente interligados (RIBAS, 2014).

Salienta-se que aspectos relacionados à estratégia de distribuição do levantador (melhor atacante, momento do jogo, mudar para prevenir adaptação do adversário, características psicológicas dos atacantes) tiveram relevante frequência nos estudos, o que é corroborado pelas características dos sujeitos das pesquisas, levantadores de alto nível. Isso também acarretou na presença de elementos complexos da dinâmica do levantamento, como posição de origem da recepção/defesa, posição ineficaz do atacante, relação saque-bloqueio do adversário e optar pelo jogador menos eficaz em relação à marcação ao melhor jogador, aspectos que demandam muita expertise para interpretação no contexto do jogo (MATIAS; GRECO, 2011a).

Com o panorama exposto, devido à pluralidade e complexidade dos elementos para decisão motriz, bem como da ausência de pesquisas que propunham sua sistematização para o ensino-aprendizagem do levantamento, este estudo dispôs-se a organizá-los a partir dos pressupostos da Praxiologia Motriz. A próxima sessão deste artigo se concentrará em realizar essa proposta. 


\section{SISTEMATIZAÇÃO DO LEVANTAMENTO: PERSPECTIVA PRAXIOLÓGICA}

Com as análises das produções contempladas nesta pesquisa, percebeu-se a carência de uma proposta de ensino para desenvolvimento do levantamento pautada em elementos de decisão motriz. Para isso, dividiu-se o processo de ensino-aprendizagem em quatro ciclos que apresentam características significativas entre si: Iniciação Esportiva; Especialização na Função; Aprofundamento na Função; Alto Nível. Para classificação, adotaram-se três categorias a partir da origem do elemento e do momento de realização da leitura, adaptado da estrutura idealizada por Greco (1998). Dessa forma, a interpretação do elemento pode ser proveniente do Conhecimento Prévio (a partir de treinos, vídeos, observação dos demais jogadores, entre outros) ou do próprio contexto do jogo, a partir da Análise Antecipada, anterior à realização do levantamento, ou da Análise Situacional, que acontece em concomitância à execução da ação. Além disso, assinalouse de qual tipo de interação motriz origina cada elemento citado a partir da legenda expressa no rodapé do quadro.

Evidencia-se que alguns elementos estão presentes em duas ou mais situações de análise, em virtude de sua relevância para a decisão motriz e para o processo de ensino-aprendizagem do ciclo. 0 quadro abaixo organiza os elementos para decisão, elencados a partir do nível de dificuldade interpretativa, propondo um caminho didático para o ensino-aprendizagem.

Quadro 2 - Ciclos de Ensino-Aprendizagem dos Elementos de Decisão Motriz do Levantador

\begin{tabular}{|c|c|c|c|}
\hline \multirow{2}{*}{ CICLOS } & \multicolumn{3}{|c|}{ ELEMENTOS PARA DECISÃO MOTRIZ } \\
\hline & Conhecimento Prévio & Análise Antecipada & Análise Situacional \\
\hline $\begin{array}{l}\text { 1 CICLO } \\
\text { (Iniciação } \\
\text { Esportiva) }\end{array}$ & - & $\frac{\text { Número de Atacantes }}{\text { Saque Adversário }}$ & $\begin{array}{l}\frac{\text { Qualidade da Recepção ou Defesa }}{\text { Adaptar a técnica e a direção do }} \\
\frac{\text { levantamento }}{\text { Posição e Tempo dos Atacantes }} \\
\text { Saque Adversário }\end{array}$ \\
\hline $\begin{array}{c}2{ }^{\circ} \text { CICLO } \\
\text { (Especialização } \\
\text { na função) }\end{array}$ & $\begin{array}{l}\frac{\text { Características dos }}{\text { Atacantes }} \\
\frac{\text { Características dos }}{\text { Passadores }} \\
\text { Bloqueio Adversário }\end{array}$ & $\frac{\text { Combinação de jogada }}{\text { BloqueióAdversárióno }}$ & 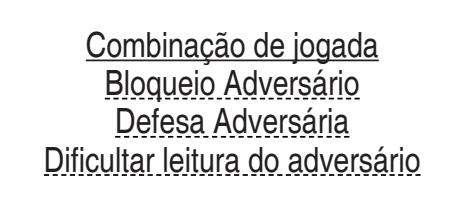 \\
\hline $\begin{array}{c}\text { 3 CICLO } \\
\text { (Aprofundamento } \\
\text { na função) }\end{array}$ & Melhor Atacante & $\begin{array}{l}\frac{\text { Posição ineficaz do }}{\text { atacante }} \\
\text { Estado Psicológico dos } \\
\text { Atacantes } \\
\text { Possiçąâdo do Levanantador } \\
\text { Adversário }\end{array}$ & 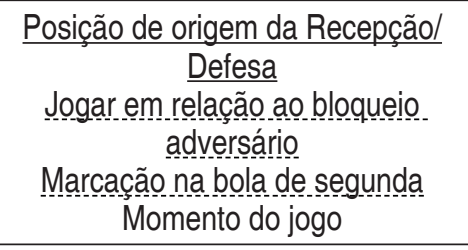 \\
\hline $\begin{array}{l}4^{\circ} \text { CICLO } \\
\text { (Alto Nível) }\end{array}$ & Treinador & $\begin{array}{c}\text { Relação saque-bló-ónueio } \\
\text { do adversário } \\
\text { Treinador }\end{array}$ & 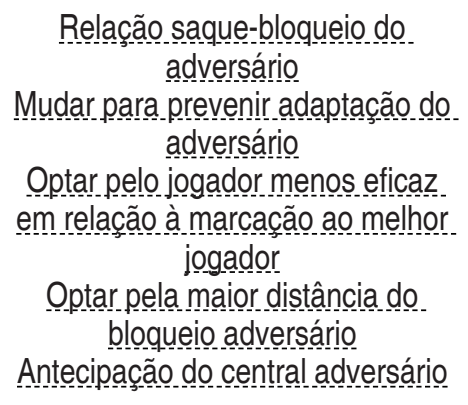 \\
\hline
\end{tabular}

Legenda: sublinhado - COOPERAÇÃO; tracejado - OPOSSICÃ̃̃O; sem marcas - SEM INTERAÇÃO DEFINIDA. 
Além de organizar os elementos para decisão motriz, é necessário apresentar subsídios norteadores ao processo de ensino-aprendizagem, mostrando-se evidente a realização de um diagnóstico desse contexto. Segundo Borges et al. (2017), há três momentos para concretizar o diagnóstico, que são Identificação (verificar as dificuldades dos alunos), Priorização (privilegiar as maiores dificuldades no desempenho dos alunos) e Seleção (eleger os conteúdos que serão ensinados). Assim, serão expostos alguns encaminhamentos metodológicos para 0 desenvolvimento dessa proposta para as características de cada ciclo.

1ํ CICLO - Iniciação Esportiva: esse ciclo contempla alunos/atletas iniciantes e, por isso, há predominância de elementos cooperativos e opositivos de fácil interpretação, em virtude da complexidade de aliar a execução das ações motrizes com as leituras de jogo na iniciação. Indicam-se exercícios que enfatizem a cooperação estabelecida pelo levantamento com recepção e ataque, mesmo que sem especialização na função do levantador, que partam da análise antecipada para a situacional, possibilitando o controle das ações motrizes e a compreensão do jogo. Outro princípio proposto é iniciar com estruturas de atividades simples, em que o aluno/atleta apenas preocupe-se com a realização da ação, inserindo os elementos à medida que a ação motriz for qualificando-se. Para o ciclo seguinte, os alunos deverão dominar as ações e decidir acertadamente a partir dos elementos.

2 CICLO - Especialização na Função: nessa etapa, começam a figurar com mesma ênfase as interações motrizes de oposição e cooperação, ao considerar que os alunos/atletas já controlam minimamente as ações motrizes, compreendem a dinâmica do jogo e poderão perceber elementos de maior dificuldade interpretativa. Fica a critério do professor selecionar jogadores específicos para função de levantador apoiado nos objetivos do trabalho em questão. Propõem-se exercícios em que a decisão motriz seja tão relevante quanto a realização da ação, com foco nas relações estabelecidas no levantamento com ataque, bloqueio e defesa. 0 auxílio do professor nessa etapa pode ser mais dirigido, trazendo à tona os elementos a serem interpretados e as decisões motrizes mais adequadas em cada situação, principalmente quanto ao bloqueio adversário. Deve-se avançar no processo quando os alunos/atletas apresentarem as leituras de jogo adequadamente articuladas com um domínio eficiente das ações motrizes, que possibilite a melhor decisão na maioria das situações.

3 CICLO - Aprofundamento na Função: nessa fase, sugere-se a denominação de um jogador específico para função de levantador, pois serão exigidos alguns aprimoramentos das ações motrizes, além de complexidade de leitura e de exercícios específicos para esse jogador. Nesse ciclo, os elementos de oposição ganham maior destaque e dificuldade de assimilação, o que demandará mais tempo, especificidade e repetição aos exercícios. 0 trabalho pedagógico deverá ter como foco a necessidade de dificultar a leitura do adversário sobre as ações que o levantador executa sempre que possível. Propõe-se a inserção de atividades que remetam diretamente às situações expressas no levantamento na dinâmica do voleibol e que enfatizem a decisão motriz a partir da leitura de elementos opositivos e de análise situacional, preferencialmente. Cabem, nessa etapa, indicações do professor quanto à relevância da distribuição do levantador para o fluxo do jogo e a sensibilidade em optar pela melhor escolha ofensiva. A condição para o ciclo seguinte é quando a relação entre decisão e ação motriz correta for muito elevada, já que o próximo ciclo necessita extremo domínio.

4CICLO-Alto Nível: esse ciclo se constitui dos mais avançados elementos para decisão motriz estabelecidos no levantamento. Essa etapa se configura de elementos basicamente 
opositivos e de análise situacional, o que eleva consideravelmente sua complexidade. Além disso, perceber a eficiência de todos os jogadores da quadra torna-se tarefa cabal para uma distribuição inteligente do levantador de alto nível. $O$ treinador enfatizará as interpretações do contexto do jogo e indicará as melhores opções para o levantador em momentos específicos, principalmente nas combinações de jogadas em relação à outra equipe. Proporá atividades dirigidas que desenvolvam os aspectos cruciais da função do levantador e das decisões motrizes em situações pontuais, em busca da excelência nas ações que se constituem nos principais espaços de aprendizagem. Em todos os exercícios o levantador deve ludibriar a outra equipe na realização do levantamento, ao compreender a necessidade da imprevisibilidade de suas ações para o sucesso da organização ofensiva.

Vale ressaltar que o objetivo dessa sistematização é servir como base para desenvolvimento do levantamento em qualquer esfera, demandando alterações a partir das características e objetivos do grupo em questão. Salienta-se que essa proposta não é engessada, os elementos podem e devem flutuar entre os diferentes ciclos, num ensino interseccionado com os objetivos estabelecidos, os métodos adotados, as abordagens escolhidas e o público em questão. Indicam-se, como possibilidade de abordagem metodológica, as proposições de González e Bracht (2012) quanto aos tipos de tarefa no processo de ensino-aprendizagem esportivo, dividida em categorias: Tipo 1 e Tipo 2 - sem interação, com desenvolvimento técnico de forma pura ou encadeada - e Tipo 3 e Tipo 4 - com interação, atentando aos princípios táticos do jogo.

\section{CONCLUSÃO}

Esta investigação dispôs-se a evidenciar e organizar os elementos para decisão motriz do levantador para o processo de ensino-aprendizagem no voleibol evidenciados na literatura, a partir dos pressupostos da Praxiologia Motriz. Percebeu-se que, mesmo que singela, a produção é extremamente relevante para a área. Contudo, há pouca variabilidade de sujeitos nas pesquisas, restringindo-se aos levantadores de alto nível. Seria válido investigar como se articulam esses elementos em outras esferas sociais de manifestação do levantamento no voleibol. Outra característica evidenciada foi que nenhum dos estudos sistematizou esses elementos para sua aplicação em aulas ou sessões de treinamento, o que instigou a proposição exposta neste artigo.

Sobre a organização didática proposta, almeja-se que ela se concretize nas atuações de professores de Educação Física que objetivem desenvolver o levantamento no voleibol com base nos elementos para decisão motriz que se estabelecem no jogo. Fica evidente que é necessária uma apropriação metodológica que dê conta desses aspectos, bem como estruturas de exercícios que possibilitem essa proposta. Indicam-se os estudos de Greco (1998) e Ribas (2014) como fontes de exercícios didáticos, em virtude das características das obras com a organização realizada.

Nesse sentido, a sistematização proposta necessita de aprofundamentos para que ganhe significado na prática pedagógica. Compreende-se que essa relação da produção científica com seu desenvolvimento no âmbito social é a principal função de uma ciência pertinente, em uma via de mão dupla que agrega congruência entre o pensar e o agir, dando propriedade à relação universidade-sociedade. 


\section{REFERÊNCIAS}

BARDIN, Laurence. Análise de Conteúdo. São Paulo: Edições 70, 2011.

BORGES, Robson Machado et al. Possibilidades de Realização do Diagnóstico no Ensino dos Esportes: uma pesquisa-ação com professores de Educação Física. Motrivivência, v. 29, n. 50, p. 104-122, 2017.

CARVALHO, Oto Moravia. Voleibol moderno: o ensino da técnica dos fundamentos: tática de ataque e defesa. Belo Horizonte: Imprensa Oficial, 1978.

DEMO, Pedro. Metodologia Científica em Ciências Sociais. São Paulo: Atlas; 1995.

DÜRRWÄCHTER, Gerhard. Voleibol: treinar jogando. Rio de Janeiro: Ao Livro Técnico, 1984.

FAGUNDES, Felipe Menezes; OLIVEIRA, Raquel Valente de; RIBAS João Francisco Magno. Saque e Recepção: Análises Praxiológicas sobre suas Influências no Voleibol. In: CONGRESO ARGENTINO, 11. y LATINOAMERICANO DE EDUCACIÓN FÍSICA Y CIENCIAS, 6. 2005. Anais... La Plata: Universidad Nacional de La Plata, 2005. Disponível em: <http:// congresoeducacionfisica.fahce.unlp.edu.ar/publicaciones110congreso/Mesa\%2004 Fagundes.pdf/ view> Acesso em: 3 jan. 2017.

FOTÍA, José. Voleibol, Lógica Interna e iniciación. Acción Motriz v. 10, p. 76 - 83, 2013.

FRANCO, Maria Laura Puglisi Barbosa. Análise de Conteúdo. 2. ed. Brasília: Liber, 2005.

FRÖHNER, Berthold. Vóleibol, juegos para el entrenamiento. 2. ed. 2. reimp. Buenos Aires: Stadium, 2012.

GIL, Antônio Carlos. Métodos e Técnicas de Pesquisa Social. 6. ed. São Paulo: Atlas, 2008.

GONZÁLEZ, Fernando Jaime; BRACHT, Valter. Metodologia do Ensino dos Esportes

Coletivos. Vitória: UFES, Núcleo de Educação Aberta e a Distância, 2012.

GRECO, Pablo Juan (Org.). Iniciação Esportiva Universal. Metodologia da Iniciação

Esportiva na Escola e no Clube. Belo Horizonte: Editora UFMG, 1998. v. 2.

LAGARDERA, Francisco Otero; LAVEGA, Pere Burgués. Introducción a la praxiología motriz. Barcelona: Paidotribo, 2003.

LAKATOS, Eva Maria; MARCONI, Marina de Andrade. Fundamentos de metodologia científica. 5. ed. São Paulo: Atlas, 2003.

MACHADO, Afonso Antônio. Voleibol: do aprender ao especializar. Rio de Janeiro: Guanabara Koogan, 2006.

MATIAS, Cristino Julio Alves da Silva; GRECO, Pablo Juan. Análise da Organização Ofensiva dos Levantadores Campeões da Superliga de Voleibol. Revista Brasileira de Ciências do Esporte, v. 33, n. 4, p. 1007-1028, out./dez. 2011b.

MATIAS, Cristino Julio Alves da Silva; GRECO, Pablo Juan. De Morgan ao Voleibol Moderno: o Sucesso do Brasil e a Relevância do Levantador. Revista Mackenzie de Educação Física e Esporte, v. 10, n. 2, p. 49-63, 2011 . 
OLIVEIRA, Denize Cristina de. Análise de Conteúdo Temático-Categorial: Uma Proposta de Sistematização. Revista Enfermagem, v. 16, n. 4, p. 569-576, out/dez. 2008.

PARLEBAS, Pierre. Juegos, deporte y sociedad: léxico de praxiología motriz. Barcelona: Paidotribo, 2001.

RIBAS, João Francisco Magno (Org.). Praxiologia motriz e voleibol: elementos para o trabalho pedagógico. ljuí: UNIJUÍ, 2014.

RIBAS, João Francisco Magno; ARAUJO, Pablo Aires; ZIMMERMANN, Marcelo Tiecher. Organizando as Ações de Ataque: Levantamento. In: RIBAS, João Francisco Magno (Org.). Praxiologia Motriz e Voleibol: Elementos para o Trabalho Pedagógico. ljuí: UNIJUÍ, 2014. p. 81 - 89.

RIBEIRO, Jorge Luis Soares. Conhecendo o Voleibol. Rio de Janeiro: Sprint, 2008.

TUBINO, Manoel José Gomes. Dimensões Sociais do Esporte. São Paulo: Cortez/Autores Associados, 1992. 
